\title{
Change management in practice: an ethnographic study of changes to contract requirements on a hospital project
}

Article

Accepted Version

Shipton, C., Hughes, W. and Tutt, D. (2014) Change management in practice: an ethnographic study of changes to contract requirements on a hospital project. Construction Management and Economics, 32 (7-8). pp. 787-803. ISSN 0144-6193 doi: https://doi.org/10.1080/01446193.2014.915336 (special Issue: ARCOM Conference Issue) Available at https://centaur.reading.ac.uk/37390/

It is advisable to refer to the publisher's version if you intend to cite from the work. See Guidance on citing.

Published version at: http://dx.doi.org/10.1080/01446193.2014.915336

To link to this article DOI: http://dx.doi.org/10.1080/01446193.2014.915336

Publisher: Taylor \& Francis

All outputs in CentAUR are protected by Intellectual Property Rights law, including copyright law. Copyright and IPR is retained by the creators or other copyright holders. Terms and conditions for use of this material are defined in the End User Agreement. 


\section{CentAUR}

Central Archive at the University of Reading

Reading's research outputs online 


\title{
Contract change management in practice: an ethnographic study of a hospital project
}

\begin{abstract}
Changes to client requirements are inevitable during construction. Industry discourse is concerned with minimising and controlling changes. However, accounts of practices involved in making changes are rare. In response to calls for more research to be undertaken into working practices, we explore how changes are made through an ethnographic study of a live hospital project. To illustrate this, a vignette of a meeting exploring the investigation of changes is presented and discussed. This represents an example from the ethnographic fieldwork, which produced many observations. There was a strong emphasis on using change management procedures contained within the contract to investigate changes, even when it was known that the change was not required. For the practitioners, this was a way of demonstrating best-practice, transparent and accountable decision-making regarding changes. Hence, concerns for following procedures sometimes overshadowed considerations about whether or not a change was required to improve the functionality of the building, which resulted in resources being wasted. However, the procedures acted as boundary objects between the communities of practice involved on the project by coordinating the work of managing changes. Insights suggest how contract procedures facilitate and impede the making of changes, which can inform policy guidance and contract drafting.
\end{abstract}

Keywords: best practice, change management, ethnography, practice, project management.

\section{Introduction}

The phenomenon of change in construction projects is widespread and familiar. Within the construction literature, project changes are often regarded as 'inevitable' (see for example 
Cox et al., 1999; Stocks and Singh, 1999; Sun and Meng, 2009). Indeed, the presence of specific clauses in standard forms of construction contract endorses this stance (Cox et al., 1999) as they provide standardised mechanisms by which to manage project change. The contract provides an important benchmark with which to define and evaluate project changes when they occur. Changes occur for many reasons, for example: as a result of a client change to requirements; in response to changing material availability; or due to unforeseen ground conditions. Client changes to contract requirements during the construction phase are the focus of this research. The dominant discourse in the construction industry is that changes are detrimental during this stage of a project due to the potential time and cost implications for the client. Moreover, existing construction management research has focused on identifying the causes and effects of changes with the intention of reducing the likelihood of their occurrence (see for example Stocks and Singh, 1999; Love and Li, 2000; Sun and Meng, 2009). Hence, the focus of many existing studies into changes on construction projects contributes to this discourse and the perceived negative connotations of changes on projects. It would appear that negative connotations of changes go largely uncontested within the existing literature on the basis that project costs are privileged as an important factor contributing to project performance. On this basis, industry discourse drowns out alternative views of changes.

Therefore, in order to gain a better understanding about changes on construction projects, there is a need to put existing assumptions and approaches to studying changes to one side. However, as empirical accounts of making changes are scarce, our understanding about these practices and the potential enactment of industry discourses remains limited. This is partly due to the overwhelming focus of existing change research in determining, quantifying and predicting the causes and effects of changes by using retrospective accounts of agreed changes. Hence, using retrospective data of agreed changes precludes the investigation of practices of making changes in a live environment. In order to address these concerns, the research sets out to explore what happens during the process of making changes to requirements on a construction project. This research aim is based on the notion that it is meaningful to gain a better understanding about the actual practices of making changes in a live project environment rather than maintaining an uncontested preoccupation with prevention and control. 
There is a growing body of construction management literature which draws on ethnographic methods to help better understand the lived experiences and practices of people in project settings (see for example, Baarts, 2009; Thiel, 2013; Tutt et al. 2013). These approaches offer fresh opportunities to explore project change in a highly immersed and sustained way. This study broadens our understanding of change management, in particular with regard to the use of procedures contained within the contract. Furthermore, it serves to recast the debate concerning practices and processes around making changes on projects. The findings of this study both challenge and reaffirm current industry discourses of change management and contract practices. This is achieved through an eight-month intensive ethnographic study of the everyday, lived nature of change in practice during a 'real world' hospital project.

\section{Changes on construction projects}

According to the Construction Industry Research and Information Association (CIRIA) best practice guide to managing change, a change refers to "an alteration or a modification to pre-existing conditions, assumptions or requirements" (Lazarus and Clifton, 2001, p.10) which applies to the design and/or construction of a project. Changes are common, their causes are numerous and they are a frequent source of conflict (Love, 2002). Nevertheless, in his study of the cost effect of changes on 161 construction projects, Love (2002) found that even projects with high change costs may come in on time and budget. This highlights the importance of how changes are managed. Many existing studies around change in construction have focused on using quantitative research methods, often using retrospective data from project documentation and reports. The aim of many of these existing studies is to identify trends in order to postulate the causes and effects of changes. For example, studies by Diekmann and Nelson (1985), Thomas and Napolitan (1995) and Hanna et al. (1999) identify some of the effects of changes based on documentary study of past projects. For example, Diekmann and Nelson (1985) studied the cost of changes on 427 public construction projects, while Thomas and Napolitan (1995) and Hanna et al. (1999) study the effect of changes on labour productivity on samples of three and 43 projects, respectively. Some studies, such as Burati et al. (1992), Cox et al. (1999), Stocks and Singh (1999), Love and Li (2000) and Ibbs et al. (2003) identify both causes and effects of changes on the projects studied. For example, Ibbs et al. (2003) quantify the time and cost effects of changes from documentary data from 67 projects and identify reasons for changes, including differences in procurement arrangements. Based on a much smaller sample, Love and $\mathrm{Li}$ 
(2000) quantify the causes and effects of changes on two projects, using Burati et al.'s (1992) categories of causes of change. While their sample size was much smaller than other studies, Love and Li (ibid.) undertook a longitudinal study where quantitative documentary data was supplemented with qualitative data from interviews. This assisted in understanding the complexities of the causes and effects of changes and filling in gaps in the documentary data. Nevertheless, many studies of changes in construction rely solely on retrospective data from documentary sources. For example, in a retrospective study of changes on three projects, Cox et al. (1999) compared the cost effects of changes belonging to different work packages. Furthermore, Cox et al.(ibid.) found that the most frequent reasons for changes, as documented in the change order request forms, were due to the employer changing their requirements, a designer omission or error in tender documents or there was new information about existing site conditions.

Although beneficial to extending our understanding of the causes and effects of changes, the approaches adopted by these studies make it difficult to gain insights into the processes of making changes. What all of these quantitative studies have in common is that they tend to treat the causes and effects of changes as discrete from other practices being exercised on the project and the context of the project. Therefore, by using such approaches, insights into the lived realities and complexity of managing changes on projects are restricted. However, it would be incorrect to assume that, on the other hand, qualitative analysis can take full account of complexity.

Nevertheless, there are many studies that use qualitative and mixed-methods approaches to understanding changes in construction, such as Love and Li (2000) in their study of the causes and effects of changes. Studies by Burati et al. (1992), Gardiner and Simmons (1992), Chan and Yeong (1995), Love et al. (1999) and Senaratne and Sexton (2008) all adopt mixed-methods approaches, combining qualitative analysis of recorded change data and qualitative analysis from interviews with participants. Many mixed-methods studies adopt a case study approach by focusing on fewer projects in greater detail which, according to Sun and Meng (2009), can assist in gathering "reliable data on cost, time and other project conditions" (p.563). However, despite attempts to use in-depth, qualitative research approaches to explore changes, the somewhat deterministic approaches of certain studies ultimately limit insights into the complexity of changes. For example, the aim of Love et al.'s (1999) longitudinal case study of changes on two projects was to develop causal influences 
diagrams to determine the causal factors of changes. Although they consider many factors which can influence changes on projects, and they identify the positive and negative and multiple effects of some factors, it is still unavoidably an attempt to pin down the causes of changes based on an assumption that solutions can then be designed and implemented to reduce the occurrence of these changes. This is based on a fundamental assumption that all, or most, changes, need to be reduced. In the case of rework errors then this is a fairly uncontroversial stance. However, as some of the rework changes described by Love et al. (1999) include client-directed improvements, this fundamental assumption about the value of changes needs to be questioned.

Uncontested assumptions about the need to minimise and control changes have arguably led to a failure in exploring the making of changes in depth. For example, in depth investigation could focus on: the detailed and contextual reasons as to why changes come about in a particular project setting and the actors involved; the processes by which changes are identified and are managed; the range of effects of changes for different actors, including beneficial effects in terms of building functionality and client satisfaction. Therefore, within the existing change management literature there has undoubtedly been an overwhelming focus on reductionism and deterministic solutions synonymous with approaches adopted by much existing construction literature, research and best-practice alike. The field of construction management is dominated by positivist research, relying on deductive and quantitative empirical research (Seymour and Rooke, 1995; Rooke et al., 1997). Similarly, Seymour et al. (1997, p.118) question the notion that "the reality of management practice can be captured in the form of a single objective account". Instead, they advocate the need to understand what managers do and how they make sense of the world, hence they advocate a focus on interpretivist investigation "that is primarily concerned with meaning rather than causality" (ibid., p.118).

\section{Change management}

According to Motawa et al. (2007), change management is an "integral part of project management" (p.368), which is reflected in their development of a change management model. Within the CIRIA best practice guide to managing change, Lazarus and Clifton (2001, p.51) define change management as "part of an overall project management framework...ensuring that any necessary changes are achieved within the approved budget, so that they represent good value for money and that authorisation to process has been 
obtained from the project sponsor". One of the key aspects of change management is the use of the change management procedures contained within the contract, which provide a standardised mechanism by which the parties can deal with change. The procedures help to facilitate, but by no means ensure, more proactive ways of managing change. According to Lazarus and Clifton (2001, p.12) effective change management "ensures that change is explicitly acknowledged and provides a framework for dealing with the consequences" in order to avoid a "chaotic" response. The CIRIA best-practice guide sets out rationale as to how and why changes should be managed effectively, which appear to be instructive but over-simplified and lacking in actual substantive advice. Moreover, the best-practice guidance is unrealistic in terms of timescales by stating that changes should be resolved within eight days, regardless of the their complexity. In this way, the CIRIA guidance does very little to dispel criticisms of best-practice guides: "the notion of 'best-practice' implies a single best way of performing any particular task, thereby shifting management theory back to the days of Taylor's (1911) scientific management" (Green, 2011, p.148). Best-practice guidance can provide useful guidelines for project management; however, prescriptive advice does not acknowledge the complexity and variability of experiences on projects.

\section{Dominant discourse and rhetoric}

The dominant discourse within the construction industry tells us that changes during construction are detrimental to a project and that changes should be minimised or, if unavoidable, tightly controlled. Changes are generally seen as a "major contributor to the problems" of the construction industry, (Lazarus and Clifton, 2001, p.9) and are seen to "reflect flaws in the planning, design, or execution of a project" (Stocks and Singh, 1999, p.252). Indeed, Stocks and Singh's (ibid.) study examining the cost of changes on projects is used as a means by which project performance, and the success of a particular design management tool, is evaluated. Hence, one of the key reasons for this negative association is the fact that changes often present additional costs for the project and potentially also additional time to be added to the programme. These effects of changes have been found by many studies, such as Chan and Yeong's (1995) study of the causes and effects of changes and strategies for reducing changes based on a survey of practitioners, and Thomas and Napolitan's (1995) study of the effect of changes on labour productivity, which can result in increased programme durations and costs for a project. Cost and time overruns on projects are synonymous with poor project performance and resultant client dissatisfaction. 
This association of changes with time and cost overruns has turned into rhetoric. Powell (2012, p.22) tells us that "change always costs money. There is the abortive work, the disruption, the lost time and the cost of the change itself'. However, this does not account for changes which actually save money, as identified by Ibbs et al. (2003) in their study of changes documented on 67 projects. Green (2011) refers to rhetoric within the improvement agenda as "sound bites" which "enter the ether of the construction improvement debate without the need for any verification... repeated so often it had become a truism" (Green, 2011, p.288). Similarly, rhetoric surrounding the nature and effects of changes often goes unchallenged. Part of the reason why such rhetoric goes unchallenged and negative attitudes towards changes are allowed to incessantly propagate is because the importance of project cost is privileged as the most important factor contributing to project performance. This is apparent in Zou and Lee's (2008) study concerning the impact of different project management practices on project change costs as a proportion of the actual project cost. Any associated impact of the use of different project management practices is subordinated to the focus on cost.

Hence, based on this dominant discourse within the construction industry, changes during construction are something to be minimised or, if unavoidable, tightly controlled. The need to minimise changes is implicit in the focus of existing studies on the negative time and cost effects of changes. In this respect, minimising changes entails avoiding changes unless they are essential for the operation of the facility. Controlling changes typically involves adopting procedures outlined in a change management model (for example, as developed by Motawa et al. (2007)) or following best-practice guidance based on change control procedures contained within the contract (for example, see Lazarus and Clifton (2001)). While there are many reasons for these views, this industry discourse drowns out alternative views of changes. Similarly, governance practices in the public sector are based on a discourse of demonstrating transparent change control and accountability (e.g. Department for Business, Innovation and Skills 2010). The discourses of change management best-practice and public sector governance are complementary and advocate strict change control.

\section{Research problem}

The process of making changes to requirements on construction projects is the focus of this study. The dominant project management discourse posits that changes should be minimised on a project or, if unavoidable, strictly and transparently controlled. However, changes may 
be required for many reasons, not all of which are detrimental to a project. For example, changing the specification to create something previously unforeseen that is more useful to the client is a positive step. In some instances, changes to the design and construction occur as a result of new technological innovations which, if implemented, can potentially improve the functionality of the building for the end users. Hence, the notion of changes on construction projects is contested. Furthermore, our understanding about these practices and the potential enactment of industry discourses remains limited. Therefore, the aim of the research is to explore practices of making changes on a live project. This is important in order to gain insights into practices around how changes are instigated, developed and agreed, rejected or left unanswered, about which our understanding is limited. Understanding project changes remains important, as change clauses continue to be included in standard-form contracts while unchallenged discourses of minimising and controlling changes prevail. Therefore, it is meaningful to gain a better understanding about practices of making changes rather than a preoccupation with prevention and control.

\section{Methodology}

\section{Research approaches in construction management}

Construction management research has long been characterised by instrumental, positivistic forms of inquiry (Seymour and Rooke, 1995; Rooke et al., 1997). The focus has overwhelmingly been on objectivity and rationality, in line with the natural sciences. These 'naturalist' or 'rationalist' approaches are suitable for certain aspects of construction management research where the focus is on mapping causal relationships between phenomena that can be appropriately quantitatively represented and empirically tested (Wing et al., 1998). As a result, construction research has been predominately focused on studying the formal and technical aspects of construction (Chan and Räisänen, 2009). However, construction management involves people and thus draws upon social science which involves understanding interactions between people as individuals and as groups. While much existing construction research has strongly focused on the formal and technical aspects of construction work, there is also "a need to capture the entirety of the construction process, of which informal and emergent processes form a large part” (Chan and Räisänen, 2009, p.907). There is a growing body of research that explores these informal aspects of construction work and they are particularly situated in the areas of knowledge, learning and managing complexity on projects. 


\section{Practice-based approaches to studying organisations and projects}

The concept of practice has increasingly become the focus of academic inquiry into organisational processes, and interest in this area has been labelled as the 'practice-turn'. Exploring practices entails exploring what actors 'do' in a particular setting and thus denotes certain methodological approaches. However, there is no single, unified practice approach and a range of different theoretical perspectives and practical interests are used. The commonality that exists between practice-based thinkers is the focus on activities carried out by people whereby practices are conceived of as "arrays of human activities" (Schatzki, 2001, p.2). Moreover, practices are not discrete and isolated but are continually interacting and interconnected.

Much attention has been paid to the study of knowledge and learning in workplace settings (Nicolini et al., 2003, p.3). By adopting a practice-based view, knowledge is no longer viewed as something that resides purely in individuals' heads; instead knowledge is brought about and institutionalised through systems of ongoing practices and is "situated in the historical, social, and cultural contexts in which it arises" (Nicolini et al., 2003, p.3). Hence practices are not isolated in space and time; they are informed by existing practices which are in turn informed by institutionalised norms and values. However, they are also informed by current contextual conditions and individual behaviour and sense-making. In this respect, enacted practices highlight shared meanings of a situation at that point in time and how these are continually being shaped: "[P]ractices are the source and carrier of meaning, language and normativity. The generation, maintenance, and transformation of these phenomena are achievements of extant practices that are realized in the public realm of actions [...] where these matters are conserved and novelty and transformation take their start" (Schatzki, 2001, p.12).

Practice-based methodological approaches in project-based settings have gained prominence partly due to a research network of academics and practitioners called Rethinking Project Management, which culminated in a special issue of the International Journal of Project Management in 2006. The need to better understand the complexity of projects was one of the key research directions that was highlighted by this network, in particular by practitioners involved who stated that "'real' projects and programmes are much more complex, unpredictable and multidimensional than the rational, deterministic model which dominates the literature" (Winter et al., 2006, p.644). Winter et al. (2006) highlight that in order to 
address these new research directions, different approaches need to be adopted in project management research which allows researchers to explore "the actual reality of projects and project management practice" (ibid., p.643). Hence, methodologically, the emphasis is on using empirical studies to understand interactions embedded in local settings. Studying project actuality entails understanding a wide range of aspects which make up social life; for example, actors' motives and sense-making processes, power asymmetries, patterns of communications and so forth, and how all these various aspects unfold over time, within networks of multiple, interlinked events (Cicmil et al., 2006).

While there have been many studies investigating informality, "much construction research hitherto merely scraped the surface" and there are calls for the use of analytical approaches which "make informal and emergent practices visible" (Chan and Räisänen, 2009, p.908). Many studies into informal practices in construction rely on interviewing, despite claiming to explore the lived realities of practitioners (for example, Alderman et al., 2005; Bresnen, 2009; Georg and Tryggestad, 2009; Green et al., 2008). Reliance on interviewing poses problems with regards to the type of data that it is possible to collect about the "lived realities' of project practices. The process of interviewing is inevitably artificial compared to observing everyday events as they occur in the setting (Hammersley and Atkinson, 1995). However, all research methods, including observational techniques, are artificial to some extent. The collection, interpretation and representation of data using ethnographic approaches is "inherently partial - committed and incomplete" (see Clifford, 1986, p.7, emphasis in original). Nevertheless, ethnography can be used to explore practices in greater depth based on naturally occurring data. Furthermore, acknowledging partiality and the inseparability of the researcher in their representations of social reality can reinforce insights rather than compromising them: "Authority comes not from being unquestionable but by acknowledging partiality" (Fortun, 2010, p.xv).

\section{Ethnography}

Ethnography has "deep and diverse roots" (Atkinson et al., 2001, p.4) and like other approaches to social research, it continues to develop across disciplines over time. Despite differences in approaches, ethnographic research can be said to be "grounded in a commitment to the first-hand experience and exploration of a particular social or cultural setting on the basis of (though not exclusively by) participant observation" (Atkinson et al., 
2001, p.4). However, many commentators regard ethnography as a written representation of culture and the strategies used to produce this final textual product are an important part of the practice of ethnography (e.g. Clifford, 1986; Van Maanen, 1988). Hence there are ontological assumptions that underlie ethnography whereby "social reality is presented, not known" (Van Maanen, 1988, p.7). Central to the representation of social reality is the role of the ethnographer. Choices and biases which influence fieldwork and the writing of the ethnography shape this representation. This has been widely acknowledged within the 'reflexive turn' in ethnography with the recognition of "ethnographic truths" as "inherently partial"' (Clifford, 1986, p.7, emphasis in original).

The author of an ethnography represents the voices of those he or she has studied. As such, ethnographies are constructions and not direct reflections of the reality they seek to represent in that time and place. Ethnography is a way of investigating social life and there is no single way in which to undertake this investigation and represent its findings, but different approaches produce different kinds of knowledge (Pink et al., 2013, p.11). It is highly suited to gaining an understanding of the everyday practices of people on projects. As each project is affected by the context in which it takes place, practices are said to be embedded and must be understood within this context. Using naturally occurring data to describe how a phenomenon is "locally constituted" helps to unpack the character of a phenomenon (Silverman, 2006, p.43). There are many ethnographies of work practice across diverse disciplines including a growing body within construction management studies. This incorporates a range of approaches, such as long-term studies involving the researcher actively participating in the setting (see Baarts' (2009) and Thiel's (2013) studies of builders on construction sites) and more targeted approaches of observation and interviewing (see Sage and Dainty's (2012) study of power in an architectural practice).This work also ranges in styles of representation and textualization, from extensive narrative descriptions such as Fletcher and Watson's (2007, p.160) so-called "ethnographic fiction science”, to more reflexive narratives and "ethnographic snapshots" of research encounters (Tutt et al., 2013). Nevertheless, ethnography is not widely used in construction management research. As such, it provides an innovative, highly immersed approach to exploring lived experiences of making changes on projects. 


\section{Research design}

The research was carried out by on eof the authors, Clare. First-person narrative is used to present Clare's first-hand account of her experiences undertaking the research that follows.

A new-build public sector hospital project was studied over a period of eight months. At the start of the fieldwork the project was in the third month of a construction programme spanning nearly three years. The project was procured via a national partnering framework arrangement. Such frameworks exist throughout the public sector in the UK. This partnering framework is mandatory for all healthcare projects over a specific threshold value. Like all projects procured under the framework, the project used the third edition of the New Engineering Contract (NEC3) Engineering and Construction Contract (ECC) Option C: target contract with activity schedule. The NEC3 is a suite of standard forms of contract that were originally used in the engineering and civil infrastructure projects, but have become increasingly used on building projects. The main stakeholders involved in the project were the client organisation and their support consultants, plus the contractor organisation and their supply chain. The client was the Health Trust organisation for that region. The project was being managed within their Estates and Planning department, primarily by the project director and the client representative. The client representative dealt with day-to-day issues on the project and liaised between the project and the client organisation, including the various end user groups. Consultants from external companies were appointed to assist the client organisation in the management of the project. A client project manager and client quantity surveyor were appointed to act as an interface between the client organisation and the contractor and their supply chain. As the project was being procured under a design-and-build arrangement, the design team were appointed and managed by the contractor organisation within their supply chain. They key people involved on the project from the contracting organisation were the contractor project manager, quantity surveyor, design manager and site manager, all of whom were based on site during construction.

Data was collected through more than 200 hours of observations, 17 interviews and document study. During the six-month observation period, I attended site several days a week, typically for the whole day. As I already had experience of managing changes in the construction industry and the culture was familiar to me, this partial immersion into the research did not pose challenges with regards to understanding basic culture practices. For example, specific construction, contract and healthcare terminology that was used on a daily basis on the 
project was generally familiar to me; it did not need to be learned as part of the ethnographic experience. Moreover, I had time to reflect on my observations in between visits to the site. Less intensive time at the research site and taking shorts periods of time out to analyse data helps to avoid the potentially "blinding" effects of "total immersion" (Thiel, 2013, p.81). Access to the project was gained through my contacts from my time spent working as a project manager for a consultancy firm. My previous experience in this role both influenced the particular choice of study and inevitably influenced approaches to fieldwork. The 'key informant' for the study was the client project manager on the hospital project, whose position facilitated the initial access to the project. It also influenced some people's attitudes towards me as some saw me as being closely associated with, and even employed by, the client project manager's company, an impression that had to be corrected.

The majority of the fieldwork was conducted at the contracting organisation's site offices, with some time spent at the client's offices. I mostly had a participant-observer role by attending and observing meetings, talking to people and generally being present when they were doing their daily work. Most of my data was collected in the form of handwritten or typed observation notes. During the meetings, my note taking was fairly inconspicuous as everybody else who attended the meeting also took notes. I developed a habit of writing notes when everybody else did, for example, when a particular action was agreed. The reason for this is that I did not want to stand out or make somebody feel uncomfortable by writing notes as they spoke if nobody else at the meeting was doing the same. Outside of the meetings, I relied on a combination of memory and quick hand written notes. As I was given a space to work in the contractor project manager's office, I was often able to hand-write notes in more detail or type up notes on my laptop very soon after having conversations. On the rare occasion that anybody asked me what I was doing, I always told them that I was writing up notes from a meeting, which I sometimes did on site to fill the time. There were regular periods of time where I was left by myself. There was a fine balance between actively trying to engage with people on site and letting them get on with their workload without interruption. Both are important for the purposes of ethnographic research. Securing ongoing access and building rapports with participants is essential for gathering data and cannot be neglected. In terms of rapport-building, some people were more amenable than others. My age (24 at the time), 'student' status and presumed inexperience were beneficial in getting people to talk about their work. With certain individuals, my role was more active and I became someone from whom updates could be requested about the progress of changes. 
However, my status as a young, female novice meant that some topics were, perhaps, not discussed.

As time went on, it became easier to talk with different people involved in the project. As my knowledge of the changes grew, it provided shared topics of interest and a common language with which to discuss them. In addition, I became a familiar face amongst the project team and so it became easier to be included in, and instigate conversations, with humour playing a big part in signalling insider-status. There were many instances where my outsider-status was more obvious, such as when doors were deliberately closed and hushed conversations were held when I was in earshot. However, such behaviours are not uncommon in a workplace setting, and there was no certainty that it was my presence or that of a colleague that provoked these reactions. Undertaking ethnographic-style research can be stressful and inevitably involves bouts of alienation and anxiety (Thiel, 2013; Pink et al., 2013). Clearly my experiences were no different. It was challenging, and sometimes exhausting, to handle the uncertainty associated with impression management and ensuring access, as well as trying to collect useful and relevant data. Nevertheless, it appeared that these instances of being excluded on the project generally became fewer as time went on. I was included in more confidential conversations, from commercially sensitive ones to workplace politics and gossip. However, certain people, like subcontractors, remained off-limits. Hence, changes that were being instigated by the client, and were dealt with by the contractor and their design team, were more visible than changes further down the supply chain between the contractor and their subcontractors.

'Going native' can be a problem associated with undertaking ethnographic research. "Once accepted by actors at a fieldwork site, researchers have to guard against 'going native': abandoning the researcher perspective and adopting the views of the actors in the setting" (Delamont, 2004, p.212). Going native is closely associated with views about the appropriate time to leave the research setting: "a good basic principle is that once the fieldsite feels like home it is time to leave...Once it is familiar, it is time to move on" (Delamont, 2004, p.214). By the end of the observation period, two months before the end of the fieldwork period, things had become very comfortable and routine on site. At this stage of my fieldwork, I was observing similar practices being continually repeated and the benefit to be gained from gathering extra data was diminishing. Things felt too comfortable, so it was time to leave. Therefore, at the beginning of the sixth month of the fieldwork I chose to finish carrying out 
observations, but continue with interviews and informal contact with project team members for a further two months. This provided useful direct access to the participants for any queries I had and helped to smooth my transition from the field. Even after the fieldwork was entirely completed, the contractor project manager 'left the door open' for me to come back to site if needed.

As the study progressed, certain project changes became the focus of the fieldwork. This iterative process of data informing the ongoing research design is typical of ethnographic research. This approach has resulted in vast amounts of qualitative data about everyday practices which contribute to building an holistic picture of the setting. Observation notes were coded in terms of events, people and changes. Specific changes were coded using emic terms routinely used by individuals in the project team. Each change provides a timeline of the process of making that change during the fieldwork period, based on the information that was available. Analysis was conducted following three approaches: first, the making of specific changes was tracked; second, a general thematic analysis of patterns of practices was undertaken across the tracked changes, which was then widened to other changes on the project; third, detailed vignettes were written from the observation notes which present detailed descriptions of what was going on in particular episodes during the fieldwork. In producing an ethnography, textual presentation is interwoven with analysis, it is part of the thinking and discovery process (Richardson and St.Pierre, 2005). The episodes presented in the vignettes were selected on the basis that they highlighted reoccurring patterns of practices that were taking place around managing changes. Hence in writing these detailed descriptions, different and more detailed aspects of these patterns emerged, which caused me to rework some of my earlier ideas. Hence, the presentation of my findings has been an analytical process of repeatedly refining the detailed descriptions and associated discussion commentaries into an account that reflects my experiences of, and subsequent thoughts about, making changes on a particular project across a period of time.

Ethnographic findings are frequently presented within vignettes which describe particular events within the fieldwork that highlight certain issues and patterns of practices. For example, Cuff (1992), Yaneva (2009) and Sage and Dainty (2012) use vignettes to present episodes of work taking place within different architectural practices. Similarly, Orr's (1996) study of photocopier machine technicians and Harper's (1998) study of work practices within the International Monetary Fund both use vignettes to highlight important, yet mundane, 
aspects of working practices. The vignettes, produced as part of a wider research project, convey interactions between different people including verbal exchanges and uses of objects, and serve to highlight the multitude of interests and perspectives which underpin a social setting. The intention of the vignettes is to give the reader an insight into what was observed and to retain some of the complexity and 'realness' of the situation. In this paper, one particular vignette is focused upon in order to provide in depth insights and to begin to unpack the practices that were repeatedly observed across project. The vignette was selected on the basis that it highlighted a range of different practices observed on the project which allows for wider discussions about change management. The discussions which follow draw upon the practices highlighted in the vignette and observed across the ethnographic study as a whole.

The vignette has been produced from a specific set of observation notes and is a representation of that particular event during the fieldwork. However, when using an ethnographic approach, it is not possible or necessary to make clear divisions between different types of data. The interviews provided rich data on which to reflect and make sense of the data being collected through observation. In this respect, the vignette presented in this paper, and the subsequent discussions of patterns of practices, are inherently informed by both the observations and interview data. Going one step further, the vignette and the findings are informed by my entire fieldwork experience. By spending a prolonged period getting to know people and observing them at work, in particular in how they interacted during meetings, I was able to draw from these experiences when producing the vignette.

The vignette that is presented depicts a particular episode from an 'internal' meeting between three members of the on-site contracting team. In the meeting the contractor team discuss ways in which they intend to go about investigating three potential client changes that have come about due to changes in building regulations. The change management procedures that operate under the contract provisions being used on the project (which are those of the NEC3) require the contractor-side to investigate potential changes when requested by the client-side. There are various contract forms that must be issued at certain times within this change management process, including Early Warning Notices (EWNs), Requests For Quotations (RFQs) and Project Manager's Instructions (PMIs). Both the client and contractor-side are obliged under the contract to issue the appropriate forms within certain timescales in order to exercise the change management procedures as per the contract. 
In order to preserve anonymity, all names and project-specific information have been changed in the vignette.

\section{A vignette of making changes}

\section{"There are no implications. We can close them out ASAP": ensuring compliance, obtaining costs and 'closing out' changes}

It is Thursday afternoon and my second week on site. Kevin told me earlier that he and Matthew, the contractor quantity surveyor, need to review some outstanding Requests for Information (RFIs) and asks if I want to "sit-in" on the meeting too. Around three o'clock Kevin rounds up Matthew and the design manager, Sarah, telling them that it is time to meet. A few minutes later, all four of us are sat in the large meeting room. Kevin, Matthew and Sarah each have copies of the RFIs to be discussed and some other paperwork in front of them, along with their open notebooks. Kevin starts the meeting by saying that they need to review three outstanding RFIs that require action from them as they potentially require Early Warning Notices (EWNs) if they have time or cost implications to the project. He explains, seemingly for my benefit, that there have been some updates to some of the British Standards which might affect the design. These updates have been identified by the electrical designer, David, and Sarah then issued them as RFIs to the former client project manager asking him whether or not the client-side wanted to incorporate the updates into the design. The response was that they wanted the contractor-side to advise them of the implications of making the changes before they could make a decision.

From the sheets in front of him, Kevin reads out the RFI reference numbers, the topics and the associated British Standard (BS) reference numbers. All four of us, including Kevin, jot down these facts in our notebooks as he speaks. "Isn't there a cut-off date in the contract?" I ask, thinking-out-loud, "and then you don't have to do any of these changes?" I immediately regret saying it as I realise that I have naively stated something that they would have already considered. Kevin agrees that there are cut-off dates and explains to me that there are different cut-off dates for different pieces of legislation on the project but the client representative, James, wants to know the implications of complying with these updates and so now they have to look into them for him. Sarah explains that they have previously done some of the work looking into the implications of the potential changes and issued this information to the client-side "but they never came back with anything" she says, shrugging 
her shoulders. Kevin points out that the new client project manager, Michael, does not want old RFIs from the design stage to drag on through the construction phase and so they now have to re-investigate the RFIs in order to "close them out", "so let's go through them one-by-one".

Kevin reads off the RFI form in front of him, "So this is about 'the services design update due to amendment 1 to BS 9548:2008"'. Sarah has the RFI form in front of her which also contains the contracting team's response that was issued to the client-side five-months ago. Reading from the sheet in front of her, she says that they advised the client that they did not need to comply with the amendment to the British Standard as it only applies to installations designed from 2012 onwards. Sarah adds that the final line of the RFI asks the client to confirm that they "are happy with this" but they have received no formal reply from them. Kevin explains that the client representative, James, has previously requested that the design team advise them of the implications of doing the update as the client director, Brian, needs to know the initial design cost and the cost of implementation in order to be able to make a decision about whether or not he wants to go ahead with the update. "This is the client's choice, they don't have to upgrade the electrical design," says Kevin, "but they won't make a decision without knowing the cost implications, understandably," he adds. Matthew adds that they will need to request some updated costs from David as the previous quote will no longer stand and he will also need to request a rough quote for implementation from the mechanical and electrical (M\&E) subcontractors. The three of them note down this mutually agreed course of action in their notebooks.

We move onto the next item. Kevin reads from his notes that it is "BS 7214 fire code update". Sarah clarifies that this is a revision to the fire code which affects the electrical power to fire and life-saving equipment. She says that it is not likely to have any implications for the project but "we must close it out". Sarah explains that David issued the technical update on email over two years ago, but he did not offer any advice or suggestions about its implications, and nothing has happened with it since. Kevin says that the easiest way to 'close-out' this issue is for them to request David to provide a cost of the design to change the current scheme based on the update and to possibly also get the implementation cost from the M\&E subcontractors. Matthew agrees and says that he will contact both parties by replying on the back of the original email issued by David two years ago so that everyone involved 
has all the information. Kevin, Sarah, Matthew and I all jot down these agreed actions in our notebooks before moving onto the next item.

Finally, the third issue is discussed. Kevin explains that the RFI refers to the "uplift to the emergency lighting lux levels". Sarah points out that the upgrade is not essential as the new British Standard affects designs done after it was issued six months ago, and the scheme was designed to the 2005 British Standard which was in place at the time and therefore this is acceptable. However, it is not that straightforward. Kevin brings up the fact that this emergency lighting issue overlaps with the value engineering (VE) of the lighting design that is also currently being reviewed. This was briefly mentioned at the fortnightly design meeting earlier this morning, where Kevin asked David to provide a statement of what was being provided in terms of emergency lighting in the revised value engineered scheme and what it would cost to redesign to upgrade this value engineered specification to meet the new British Standard. Kevin says that David should now be working on that so they can issue to it the client-side soon. Matthew says that he will also ask the M\&E subcontractors to provide an estimated cost for the implementation of the upgrade. He adds that they would need to advise the client-side that any saving from the downgrading of the lighting specification as part of the VE would then be offset if they chose to comply with the new requirement, so there would not be a saving. We all jot down the actions to be taken to progress the third RFI issue, which are very similar to the previous two.

It is now four o'clock; the meeting has gone on for an hour and is coming to an end as the three issues have been discussed. Kevin wraps up the meeting with a quick summary of the actions for each issue, all of which are identical: obtaining estimates for the work. Kevin points out that there is a risk register review meeting with the client on Tuesday and it would be good to get these first estimates in time so they can discuss them at the meeting with the client project manager and client representative. Matthew agrees and says he will ask for "quick RFQs" from David and "an idea of the implementation cost" from the subcontractors.

Once the meeting is finished everyone quickly disbands to go back to their respective offices to finish the last hour or so of the day. As we are both packing up to leave at $5 \mathrm{pm}$ I get the opportunity to talk about this afternoons meeting and ask Kevin what he thinks will be the outcome of the upgraded standards: "Clearly there are no implications for the project as they do not need to comply with these updates and changes due to the cut-off date for the design. So the answer is simple, there are no implications. We can close them out ASAP," Kevin 
says, matter-of-factly. Kevin emphasises that it is often people in the client estates department who bring up these technical issues and the contractor-side are told to investigate the implications "but all these things add up! The design team works to an activity schedule and anytime over it they want to be paid." Kevin explains that Matthew "will only get very quick estimates for the work, like 'it's approximately 20 grand', so we don't spend time on it and the client can make a decision". However, Kevin stresses the point further, "The problem is, James does not realise the cost implications of saying 'can you provide a cost for this or that'," he sighs. If a designer spends five hours at 70 quid an hour that's 350 quid on half a day's work," he says, shrugging his shoulders in defeat.

\section{Discussion}

\section{Reinforcing discourses of change management: minimise and control}

This vignette provides insights into the 'actuality of projects' (Cicmil et al., 2006) by depicting typical ways in which potential changes are investigated on the project. The purpose of the review meeting is for people in the contractor team to determine what information needs to be provided to the client-side so that they can make a decision about whether or not they want to go ahead with the changes. The overarching focus of the discussions is on avoiding change by emphasising that the changes are not mandatory from a compliance perspective. In addition, the contractor project manager refers to having to use the "British Standards which were current when the design was being done and signed-off". The concept of signing-off designs is repeatedly used throughout the project, and here it is used as a way of fixing the design at a set time in order to minimise potential changes. Much of the existing change literature and guidance present changes as contributing to problems on projects, reflecting flaws in the execution of a project and hence should only be carried out where they are unavoidable (e.g. Stocks and Singh, 1999; Lazarus and Clifton, 2001). Hence the focus of the meeting enacts on avoiding changes reinforce these negative conceptualisations of changes which dominate the existing literature and guidance.

Contract conventions set out standardised ways of managing changes and establish sanctions for not using them. For example, there are specific timescales for issuing contract quotations and instructions and the parties can become 'time-barred' if they are not met. In addition, 
incorrect use of the contract can be regarded as poor project management practice which can have reputational and commercial consequences. This is particularly pertinent on this high-profile public project where the contract procedures have to be followed for auditing purposes. Moreover, contract practices establish norms of conduct of making changes that are informed by the traditions and conventions of the project organisation and the construction industry. The dominant industry discourse, which advocates that changes should be minimised and, if unavoidable, tightly controlled shape these norms and subsequent interactions on the project. By pursuing sign-off of designs and closely following contract procedures in order to minimise and control changes, individuals in the project team reaffirm and reproduce this dominant industry discourse. Contract procedures were also used due to concerns for demonstrating transparency and accountability, thereby reinforcing dominant discourses within the public sector with regards to value for money and transparency of public spending.

However, focusing on the process of investigating and making changes can overshadow concerns about what a change actually entails. For example, in the meeting the implications of the change in terms of potentially improving the functionality of the building are not discussed. Instead the focus of the discussions and actions to progress the potential changes is on demonstrating compliance and providing cost estimates. In the existing change literature and guidance, cost is judged as one of the key factors in decision-making about changes (e.g. Zou and Lee, 2008). By providing the client-side with the cost implications, the individuals in the contractor team are performing their role in advising the client of "the implications" of the change. This information can then allow the client-side to reject and "close out" the potential change and demonstrate that the decision has been informed by the cost implications and the fact that the current design is deemed to be compliant. By reproducing discourses concerned with minimising and controlling changes, potential changes are being investigated in a way that emphasises demonstrating best-practice and accountability while the content and relevance of the potential change are often overlooked

\section{Change management as a defence mechanism}

For every change that is formally instructed under the contract, there are often many other changes that are considered but ultimately rejected. These potential changes often go through the same lengthy process of development as the changes that are eventually instructed, and consequently use resources that do not directly contribute to the finished building. In many 
respects this is unavoidable as due to high levels of uncertainty which is inherent in construction projects, information and requirements cannot be crystallised at the outset; the fact that potential changes have to be instigated during the construction phase is testament to that. There are different types of potential changes: changes that have to be or are very likely to be instructed; changes that are desired but are unlikely to be economically viable to result in an instruction; and changes that are investigated but with no, or very little, intention of actually instructing them. Across the project, the client-side frequently requested implications and proposals for potential changes without much upfront consideration about whether or not they are likely to implement them. In this vignette, the intention is to provide the client-side with quick estimates of the costs of the changes as the contractor team know that the changes are not required on the basis that the current design is compliant without conforming to the updated legislation.

This vignette captures the frustrations of the contractor project manager in encountering the client representative's proposals, which are made without an appreciation of the amount of resources used to investigate potential changes. Every time a potential change is instigated by the client-side, it is unavoidable that some degree of rework to explore the design options and costs exercises to price these options is needed. Unless a change is instructed, the upfront work of the design team is not compensated. Regardless of whether a change is instructed, the contractor team is not paid for their involvement in managing the change process and producing estimates as the client-side deems this as part of their role and regular duties required on the project. This contributed to a general attitude of negativity towards changes from the perspective of the contracting team. This in turn contributed to a focus on minimising the number of changes to be investigated, which resonates with and reinforces existing discourses of negativity towards changes.

It is sometimes the case that there is no intention to instruct the potential change, but the client-side has to be able to demonstrate that the change has gone through the correct procedure of investigation and been rejected based on consideration of the costs and benefits to the project. This is the practice being followed in the meeting whereby the individuals in the contractor team known they need to go through the motions of investigating the change in order that it can be 'closed out'. The reason being is that this high-profile public sector project is subject to scrutiny and audits, therefore, demonstrating transparency and accountability for decisions is deemed to be very important. Individuals in the project team 
were concerned for both their professional and personal accountability for decisions. Prosecution of companies and individuals involved in NHS projects are not uncommon where buildings faults have been incurred as a result of past decisions relating to the building. Sometimes such faults can result in staff, patients or the general public being injured or, in some cases, killed. Hence, decisions about changes to the building on this type of project can be the difference between life and death. Therefore, a number of changes due to updates to building regulations and other legislation were investigated on the project in order to demonstrate that these changes had been considered according to the contract procedures. These potential changes could then be rejected through demonstrating the compliance of the existing design and the costs to the project to implement the change. In essence, the individuals in the project team were seeking to 'cover their own backs' and ensure accountability for decisions surrounding potential changes in this high risk environment.

In this respect, the concept of potential changes challenges the conventional idea about what a change is on a project and why it comes about. As shown, it is overly simplistic to think of changes as being instigated due to a need to change project requirements. Instead, potential changes are considered for many reasons, including those which have nothing to do with an intention to change project requirements. The underlying assumption of the existing change management literature is that changes that are investigated are genuinely required; they are not potential changes for which there is no, or very little, intention of instructing. In depth, ethnographic access to the actual management of changes over a series of several months allowed these multiple purposes behind the investigation of several changes to be revealed. This highlighted issues concerning transparency, compliance and accountability which underpin change management, which has not been acknowledged in existing literature. These concerns of the individuals in the project team are essentially defensive and risk-adverse, yet still rational. Nevertheless, this notion of change management as a reactive defence mechanism is entirely different to that which is depicted in the change literature and contract guidance.

The reality of projects and project management practice take place "within an array of social agenda, practices, stakeholder relations, politics and power" (Winter et al., 2006, p.642). The existing change literature does not acknowledge the organisational context in which managing changes take place as arguably no other study has looked close enough to see beneath the veneer of the everyday practices of using the contract procedures to understand 
the purposes that they sometimes fulfill. Ironically, one of the self-proclaimed characteristics of the NEC form of contract is that it is a "stimulus to good management" such that "every procedure has been designed so that its implementation should contribute to, rather than detract from, the effectiveness of management of the work (NEC3, 2005, p.3). Despite this well-intended aim, the change management procedures contained within the contract are sometimes used to investigate and reject changes for accountability purposes, which use project resources that do not have any direct contribution to the finished building. In these instances, the change management procedures are used as a means of demonstrating best-practice and accountable decision-making. Thus, contract procedures, paradoxically, contribute to wasteful and inefficient project management practices.

\section{Change management contract procedures as boundary objects}

The discussions presented in the vignette highlight the knowledge that is used when dealing with potential changes. Frequently, the individuals in the project team managing the process of making changes do not have the technical knowledge to judge whether or not a potential change should be accepted or rejected. For example, the contractor project manager is able to state what a particular change is about from the information contained in the RFI forms and associated emails, but is unable to go into any more detail than this. The managers dealing with the management of changes have to rely upon the designers and other specialists to provide information on which decisions can be made. Therefore, these managers focus on what is required for their role in the project. With regards to managing changes, this chiefly comprises obtaining and evaluating the time and cost implications of a change and doing so in an accountable and transparent way. In addition, these individuals do not have the authority to make decisions about changes. Instead they assemble the information on which the client director (or a board of project committee members) can make the ultimate decision.

Hence, the change management procedures contained within the contract provide a structured way of carrying out these responsibilities and do not necessarily require in depth technical knowledge about the specific changes that are being investigated. In this respect, the change management procedures contained within the contract act as a boundary object between the various professional disciplines involved on the project. Boundary objects are used to

"support connections between different practices" and across communities, and include artifacts, discourses and processes (Wenger, 2003, p.88). Boundaries between different communities of practice are of particular significance when exploring project-based 
organisations which often consist of multiple, interacting communities. As a boundary object, the contract procedures help to coordinate the work of managing changes; they transfer knowledge across the boundaries between the individuals on both the client and contractor-side, including, project managers, designers and even subcontractors and end-users who contribute to the change process.

The various professional disciplines on the project constitute different 'communities of practice'. These are culturally-defined communities in and between which learning takes place, which have a shared repertoire consisting of "communal resources - language, routines, sensibilities, artifacts, tools, stories, styles, and so forth" (Wenger, 2003, p.80). The technical language and understanding associated with the issues raised in the RFI forms is beyond the technical knowledge of the contractor project manager, quantity surveyor and design manager. Instead, they communicate using the shared language represented by the basic descriptions contained in the RFI forms, the RFI numbering and the common understanding of the process that needed to be followed in order to progress the investigation of the potential changes. Except for the brief descriptions in the RFI forms, the potential changes could have been about almost anything and it would not have really mattered; the processes that need to be followed to investigate them would still be the same. Following these processes meant the potential changes could progress that one step further towards being accepted or rejected by the client-side. The people in the contractor team had done what they needed to do at that point in time with regards to managing this process on the project.

Objects are of particular interest and fulfil roles of complexity on projects as they can serve multiple communities of practice. "When a boundary object serves multiple constituencies, each has only partial control over interpretation of the object... [artifacts] are in fact nexus of perspectives, and that it is often in the meeting of these perspectives that artifacts obtain their meanings" (Wenger, 1998, p.108). On a construction project, contracts and the processes they attempt to enforce are boundary objects serving multiple constituencies. The meanings associated with particular aspects of a contract process can be a source of conflict due to differences and incompatibility of perspectives belonging to the parties involved. This difference in interpretation of objects can be seen in the differences between the contractor team's original response to the RFIs (that is, informing the client that the changes in legislation did not apply to the project as the design was compliant), and the client's request 
that the contractor team advise them of 'the implications' of the changes. The contractor team interpret 'the implications' to be the cost implications, and hence in this vignette they plan how they will obtain cost estimates for the client-side. In this respect, the use of contract procedures to transfer knowledge across boundaries of communities of practice highlights the multiple interests and understandings on the project.

\section{Thinking-out-loud and personal biases}

My evolving role as a researcher on the project is particularly apparent in this vignette, which took place during the first month of the fieldwork. From my own experience as a project manager working on similar projects, my own default stance was to question if there was a cut-off date in the contract after which they did not need to comply with changes in legislation. In this sense, my own biases also, inadvertently, reflected the dominant industry discourse of minimising and controlling changes. Nevertheless, I was able to acknowledge these biases and, importantly, question where they had come from in the first place. In considering my own biases, it led me to consider those of other individuals in the project and the dominant industry discourses that prevailed. Moreover, by the end of this particular RFI review meeting I was dissatisfied by the apparent lack of progress that had been made during the meeting. Despite my previous experience of these situations, I had still expected the discussions to be more centered around questions of functionality and evaluating the necessity of the potential changes rather than focusing on proving compliancy and obtaining cost estimates. However, as time progressed during the fieldwork, these types of discussions were repeated for numerous other changes, and I gradually became accustomed to them as a normal part of everyday life on the project. Moreover, by understanding the importance of the different roles of individuals in the project team and their respective knowledge bases, I could appreciate why different individuals focused on different aspects when investigating and making changes.

\section{Limitations}

With regards to the applicability of the findings, the research is specific to the local context in which it was carried out. For example, the findings are specific to the type of project and contract arrangement. In this case it was a large public sector healthcare project using the NEC3 Engineering and Construction Contract and the change procedures that are implemented under this contract. Furthermore, as practices are constantly evolving, the 
findings are specific to the time and stage in the project lifecycle at which the research was carried out. The fieldwork was undertaken at the start of the construction stage on the project. Hence many of the potential changes being investigated at that point would not be physically constructed for quite a long time. There were few changes for which decisions were deemed to be critical, that is, a delay in the decisions regarding an aspect of the change would result in a part of the construction being delayed.

The study is specific to the type of changes that it explores. It became apparent during the course of the fieldwork that client-led changes constituted the majority of the changes being investigated and implemented on the project. At this time on the project, contractor changes were rare. Hence the findings relate specifically to client-led changes to requirements. These constitute one type of change, amongst a range of others, which can occur on a project. Furthermore, in order to satisfy the aim of the study, the research was specifically focused on following changes. Exploring the making of different types of changes could also be considered in future further studies. Changes like weather events and contractor-led changes would potentially reveal different practices of managing changes that were previously unseen.

The focus of the fieldwork was concentrated on the interactions at the top-tier of the construction supply chain. This entailed interactions between the client and contractor organisations and their respective advisors, including the design team and the client's advisors. As a result of this, not all individuals involved in the project were encountered during the fieldwork. However, it is unlikely that any study would be able to ensure that every single individual involved was encountered, and encountered in a way that provided useful insights. Many individuals remain in the background, away from the regular cycle of meetings and project-related correspondence. For example, the designers who comprised the 'design team' on the project were actually leading teams of designers on the project. Hence, these teams of designers were effectively working in their respective offices in the background on the project, yet part of their work entails making changes. These individuals were not present at the client or contractor offices during the fieldwork period. Moreover, they were only ever briefly, and infrequently, mentioned on the project. Hence, the study does not reflect the working practices of those people managing changes on the project that were outside of the immediate project team that gathered at the client and contractor offices on a regular basis. Moreover, there are further tiers in the supply chain that were not 
explored, such as the interactions between the contractor and their subcontractors. Hence, the findings are specific in terms of the type of people and the working practices that were experienced.

The ethnographic method adopted imposes various specificities on the findings. For example, my access, evolving role and behaviour in the field, along with choices of data collection techniques influenced the nature of the research and the data collected. However, the type of role that I could adopt on the project was restricted. For example, it was difficult to obtain a participant role in an office setting where work roles were already clearly assigned and filled according to job titles. In a similar vein, if I had gained access to a study via a different type of gatekeeper, for example through someone less senior with the project, then my role and ongoing access to the field may have been different. In addition, my age, gender, previous work experience and current education background inevitably shaped the study. Therefore, the research data collection and subsequent analyses are specific to me, as a researcher, as they are influenced by how I was perceived and how I perceived others, plus my own personal biases.

\section{Conclusions}

The aim was to explore how changes are made on a construction project. This aim was founded on a call for more research into project practices in order to provide practical and theoretical understandings of the lived experiences of individuals in local settings. There was a need to better understand work practices rather than to follow the unchallenged discourses that changes should be minimised and strictly controlled. Using an ethnographic approach, the making of changes in a hospital project is explored and a vignette of a specific meeting investigating changes is presented and discussed. The findings highlight the importance of contract procedures on the project for individuals to control and minimise changes and demonstrate transparency and accountability. In this respect, the dominant industry discourse of minimising and controlling changes both influenced practices, and was reaffirmed by them. However, there were also challenges to dominant discourses observed across the project, evident in informal practices of controlling changes using the contract procedures. Furthermore, the active pursuit of changes by end-users also challenged dominant discourses of minimising changes. Such alternative discourses have not been presented in this paper but will be addressed in further publications. 
At times this dominant discourse to minimise changes overshadowed actors' considerations about the requirements of the change, and whether or not the change was required to improve the functionality of the building. Sometimes the investigation of changes were motivated by concerns to demonstrate that best-practice change management procedures have been followed even when it is known that changes are unlikely to go ahead. Investigating these types of potential changes resulted in resources being wasted. Paradoxically, this stands in stark contrast to industry discourses associated with using contract procedures to control changes in order to improve project performance and efficiency. Hence, investigating potential changes in order to demonstrate best-practice, and transparent and accountable decision-making can be inefficient and wasteful. The study highlights these issues as underpinning change management on the high-risk and risk-adverse project environment, yet they have not been acknowledged in existing change literature. The notion of change management as a reactive defence mechanism is entirely different to that which is depicted in the change literature and contract guidance. However, investigating changes by focusing on the cost implications is in line with industry discourses, whereby cost is judged as one of the key factors in decision-making. The opportunities represented by potential changes were rarely considered on the project.

Following norms of project management and public sector best-practice, the need to demonstrate compliance and transparency were often prioritised by certain individuals in the project team, with considerations about the change being secondary. This highlights how these concerns can be detrimental to a project by shifting the focus from the actual change, and potential improvements to the building, to the process of making the change and accountability. Nevertheless, the change management procedures contained within the contract act as boundary objects between the various professional disciplines, or communities of practice, involved on the project by coordinating the work of managing changes. In this respect, the contract procedures contributed to the control of changes. The contract procedures provide a structured way of managing changes which do not necessarily require in depth technical knowledge about the specific changes that are being investigated. This helps to overcome differences in the communal resources, such as knowledge and language, between the multiple, interacting communities of practice on the project. Insights gained from the in-depth, ethnographic study suggest how contract procedures are used in practice to both facilitate and impede the making of changes. These insights into practices can potentially inform contract drafting and improve guidance for managing projects. 


\section{Acknowledgements}

The research for this paper was carried out under a Doctoral Studentship funded by the Engineering and Physical Sciences Research Council (EPSRC).

\section{References}

Alderman, N., Ivory, C., McLoughlin, I., and Vaughan, R. (2005) Sense-making as a process within complex service-led projects. International Journal of Project Management, 23(5), 380-385.

Atkinson, P, Coffey, A, Delamont, S, Lofland, J and Lofland, L (2001) Editorial introduction. In: P. Atkinson, A. Coffey, S. Delamont, J. Lofland and L. Lofland, (eds.) Handbook of ethnography. London: SAGE Publications.

Baarts, C (2009) Collective individualism: the informal and emergent dynamics of practising safety in a high-risk work environment. Construction Management and Economics, 27(10), 949-957.

Bresnen, M. (2009) Living the dream? Understanding partnering as emergent practice. Construction Management and Economics, 27(10), 923-933.

Burati, L J, Farrington, J J and Ledbetter, W B (1992) Cause of quality deviation in design and construction. Journal of Construction Engineering and Management, 118(1), 34-49.

Chan, A. P., and Yeong, C. M. (1995) A comparison of strategies for reducing variations. Construction Management and Economics, 13(6), 467-473.

Chan, P W and Räisänen, C (2009) Editorial: informality and emergence in construction. Construction Management and Economics, 27(10), 907-912.

Cicmil, S, Williams, T, Thomas, J and Hodgson, D (2006) Rethinking project management: researching the actuality of projects. International Journal of Project Management, 24(8), $675-686$

Clifford, J (1986) Introduction: partial truths. In: J. Clifford and G.E. Marcus, (eds.) Writing culture: the poetics and politics of ethnography. London: University of California Press.

Cox, I D, Morris, J P, Rogerson, J H and Jared, G E (1999) A quantitative study of post contract award design changes in construction. Construction Management and Economics, 17(4), $427-$ 439.

Cuff, D. (1992) Architecture: The Story of Practice, MIT Press, London.

Delamont, S. (2004) Ethnography and participant observation, in Seale, C. Gobo, G., Gubrium, J.F. and Silverman, D. (eds) Qualitative Research Practice, Sage, London. 
Department for Business, Innovation and Skills (2010) "Guidelines for managing projects. How to organise, plan and control projects". London: HMSO.

Diekmann, J. E., and Nelson, M. C. (1985) Construction claims: frequency and severity. Journal of Construction Engineering and Management, 111(1), 74-81.

Fletcher, D and Watson, T (2007) Voice, silence and the business of construction: loud and quiet voices in the construction of personal, organizational and social realities. Organization, 14(2), $155-174$

Fortun, K. (2010). Of writing culture, 2020 Foreword to the twenty-fifth anniversary edition, in Clifford, J. and Marcus, G.E. (eds) Writing culture: the poetics and politics of ethnography. 25th anniversary edition. University of California Press, London, pp.vii-xxii.

Gardiner, P. D., and Simmons, J. E. (1992) Analysis of conflict and change in construction projects. Construction Management and Economics, 10(6), 459-478.

Georg, S. and Tryggestad, K. (2009) On the emergence of roles in construction: the qualculative role of project management. Construction Management and Economics, 27(10), 969-981.

Green, S. D. (2011). Making sense of construction improvement. Wiley: London.

Green, S.D., Harty, C., Elmualim, A.A., Larsen, G.D. and Kao, C.C. (2008) On the discourse of construction competitiveness. Building Research \& Information. 36(5), 426-435.

Hammersley, M. and Atkinson, P. (1995) Ethnography: principles in practice. 2nd ed. Routledge, Oxford.

Hanna, A. S., Russell, J. S., and Vandenberg, P. J. (1999) The impact of change orders on mechanical construction labour efficiency. Construction Management and Economics, 17(6), 721-730.

Ibbs, C. W., Kwak, Y. H., Ng, T., and Odabasi, A. M. (2003) Project delivery systems and project change: Quantitative analysis. Journal of Construction Engineering and Management, 129(4), 382-387.

Lazarus, D and Clifton, R (2001) Managing project change. A best practice guide. London: Construction Industry Research and Information Association.

Love, P.E.D., Mandal, P and Li, H (1999) Determining the causal structure of rework influences in construction. Construction Management and Economics, 17(4), 505-517.

Love, P.E.D., and Li, H. (2000) Quantifying the causes and costs of rework in construction. Construction Management and Economics, 18(4), 479-490.

Love, P.E.D. (2002) Influence of project type and procurement method on rework costs in building construction projects. Journal of Construction Engineering and Management, 128(1), 18-29. 
Motawa, I. A., Anumba, C. J., Lee, S., and Peña-Mora, F. (2007) An integrated system for change management in construction. Automation in Construction, 16(3), 368-377.

Nicolini, D., Gherardi, S., and Yanow, D. (2003) Introduction: towards a practice-based view of knowing and learning in organizations. In. D. Nicolini, S. Gherardi and D. Yanow (eds.). Knowing in organizations: A practice-based approach. ME Sharpe: London. p.3-31.

Pink, S., Tutt, D. and Dainty, A. (2013) Introducing ethnographic research in the construction industry, in: Pink, S., Tutt, D. and Dainty, A. (eds) Ethnographic research in the construction industry. Routledge, Abingdon, pp.1-22.

Powell, G. (2012) Construction Contract Preparation and Management: From Concept to Completion. Palgrave Macmillan, Basingstoke

Richardson, L. and St Pierre, E. A. (2005) Writing: a method of inquiry, in Denzin, N. K. and Lincoln, Y. S. (eds) The Sage handbook of qualitative research. 3rd ed. Sage, London, pp.959-978.

Rooke, J., Seymour, D., and Crook, D. (1997) Preserving methodological consistency: a reply to Raftery, McGeorge and Walters. Construction Management and Economics, 15(5), 491-494.

Sage, D J and Dainty, A (2012) Understanding power within project work: the neglected role of material and embodied registers. Engineering Project Organization Journal, 2(4), 202-15.

Schatzki, T R (2001) Introduction: practice theory. In: T.R. Schatzki, K. Knorr Cetina and E. Savigny, (eds.) The practice turn in contemporary theory. London: Routledge.

Senaratne S and Sexton M (2008) Managing construction project change: a knowledge management perspective, Construction Management and Economics, 26(12), 1303-11.

Seymour, D., Crook, D., and Rooke, J. (1997) The role of theory in construction management: a call for debate. Construction Management and Economics, 15(1), 117-119.

Silverman, D (2006) Interpreting qualitative data: methods for analysing talk, text and interaction. 3ed. London: SAGE Publications.

Stocks, S N and Singh, A (1999) Studies on the impact of functional analysis concept design on reduction in change orders. Construction Management and Economics, 17(3), 251-267.

Sun, $M$ and Meng, X (2009) Taxonomy for change causes and effects in construction projects. International Journal of Project Management, 27(6), 560-572.

Thiel, D. (2013) Ethnography and flux: identity and epistemology in construction fieldwork, in Pink, S., Tutt, D.E. and Dainty, A. (eds) Ethnographic research in the construction industry. Routledge, London, pp.73-90. 
Thomas, H. R., and Napolitan, C. L. (1995) Quantitative effects of construction changes on labor productivity. Journal of Construction Engineering and Management, 121(3), 290-296.

Tutt, D., Pink, S., Dainty, A. and Gibb, A. (2013) 'We've got our own language': the communication practices of migrant workers in the UK construction industry. In. S. Pink, D.E. Tutt and A. Dainty (eds.) Ethnographic research in the construction industry. Routledge: London. p.4057

Van Maanen, J (1988) Tales of the field: on writing ethnography. London: The University of Chicago Press.

Wenger, E. (1998) Communities of practice: Learning, meaning, and identity. Cambridge University Press.

Wenger, E. (2003) Communities of practice and social learning systems. In. D. Nicolini, S. Gherardi and D. Yanow (eds.). Knowing in organizations: A practice-based approach. ME Sharpe: London, p.76-99.

Wing, C. K., Raftery, J., and Walker, A. (1998) The baby and the bathwater: research methods in construction management. Construction Management and Economics, 16(1), 99-104.

Winter, M., Smith, C., Morris, P., and Cicmil, S. (2006) Directions for future research in project management: the main findings of a UK government-funded research network. International Journal of Project Management, 24(8), 638-649.

Yaneva, A. (2009). Made by the Office for Metropolitan Architecture: an ethnography of design. Publishers, Rotterdam.

Zou, Y. and Lee, S.H (2008) The impacts of change management practices on project change cost performance, Construction Management and Economics, 26(4), 387-393. 